\title{
Arts for the Blues - A New Creative Psychological Therapy for Depression
}

Ailsa Parsons, University of Salford (Corresponding author. Email: a.s.parsons@salford.ac.uk)

Dr Joanna Omylinska-Thurston, Greater Manchester Mental Health Foundation NHS Trust

Professor Vicky Karkou, Edge Hill University

Julianne Harlow, Edge Hill University

Shelly Haslam, Edge Hill University

Jessica Hobson, Edge Hill University

Kerry Nair, Greater Manchester Mental Health NHS Trust

Dr Linda Dubrow-Marshall, University of Salford

Dr Scott Thurston, University of Salford

Julia Griffin, Edge Hill University

\begin{abstract}
Routinely prescribed psychological therapies for depression are not always effective. Arts therapies, particularly Dance Movement Psychotherapy, may offer additional therapeutic mechanisms for depression. Therefore, client-reported helpful factors from various therapy types, along with client preferences, are key in devising new therapeutic interventions. We present a framework for a new pluralistic 'meta-approach' of therapy for depression, based on an interdisciplinary thematic synthesis (Thomas \& Harden, 2008) of active ingredients from both talking therapies and creative approaches. Lastly, we offer an example group therapy workshop based on this approach, to be piloted with clients and practitioners within an NHS mental health service. Further research is required to evaluate this pilot and to devise a full treatment for trialling within the service.
\end{abstract}

Keywords: Psychotherapy; Depression; Pluralistic; Arts therapies; Creative approaches 


\section{Introduction}

Depression affects $7.8 \%$ of the UK population (Mental Health Foundation, 2016). Although NICE (2018) recommends several psychological interventions, in practice a combination of CognitiveBehavioural Therapy (CBT) along with anti-depressant medication is often offered as first line treatment for depression. Improving Access to Psychological Therapies (IAPT) service outcomes data shows that of those finishing treatments, people in less deprived areas were more likely to show improvement in their condition and move towards recovery (58\%) when compared to those living in more deprived areas (39\%) (Parliament, House of Commons, 2018). As CBT is the main therapeutic intervention for depression, it is possible to conclude that it may have a limited effect on clients' recovery, especially in deprived areas. Given the high levels of investment in IAPT, these findings have financial and ethical implications and require further investigation.

A survey undertaken by the charity Mind demonstrated that $70 \%$ of service users found arts psychotherapies (Art, Music, Drama and Dance Movement Psychotherapy [DMP]) beneficial and rated them in the top three treatments of choice (Dudley, 2006). A UK survey (Williams \& Scott, 2009) also indicated that service users wanted more access to arts psychotherapies. However, while there is a marked increase in research in this area (Zubala \& Karkou, 2018), there remains limited access to these creative interventions within IAPT. Arts psychotherapies are used for therapeutic change within an established therapeutic relationship, the process being facilitated by a qualified practitioner (Karkou \& Sanderson, 2006). The development of a new evidence-based intervention for depression from arts and mainstream talking therapies has the potential to contribute to depression recovery for those clients who are functioning well enough to be able to engage with such treatment, as opposed to those in a catatonic or acutely distressed state.

DMP is an arts psychotherapy which through a movement or creative act, it is possible to express, explore, interact, understand and derive meaning (Meekums, 2002). It is possible that in addition to the value ascribed to the creative component, physical activity levels could be enhanced, leading to increased secretion of pain-relieving endorphins, reduced cortisol levels and increased production and release of monoamines in the brain, all of which contribute to a 'feel-good' effect (Jola \& Calmeiro, 2017). In the treatment of depression, Karkou, Genetti, Zubala and Meekums (in press) suggest that active connection with the moving body leads to a sense of agency and vitality. Through mirroring and physical attunement and the use of props, rhythm and imagination, relationships can be fostered as an essential means of tackling social isolation and loneliness. Unearthing difficult feelings through imagery, communicating them through symbolic movement and creating links between new discoveries and one's experiences are important factors that operate at an intra-psychic level. Stern's (1995) vitality dynamics theory holds that humans experience affective states and life events physically through a variety of perception parameters such as; movement, time, force, space, and intention. Verbally, these 
states and events may be described imaginatively as; gliding, swinging, pushing or otherwise. By purposely engaging and interacting with dimensions of experience through physical and artistic representations, individuals can push out of habitual/default ways of processing personal material, deepening their self-awareness.

Prior to the commencement of this project three of the authors of this paper (JOT, ST and VK) began experimenting with expressive arts as a way of getting to know one another. This led to the development of a process, starting with a body scan and identifying body information. Subsequently, each author took turns to express their embodied material in one modality (e.g. writing, movement, drawing, talking), while the others witnessed this and expressed their feedback in different modalities. Reflecting on this process they discovered common themes as the group dynamic was activated. This helped to enrich and deepen the connection between them and led to the creation of this project.

These experimentations demonstrated the usefulness of diverse creative methods and their potential value for clients. The authors reflected that in practice psychotherapists engage with clients via these media in order to comprehend the full 'Gestalt' of vitality dynamics surrounding the client's phenomenological reality, past and present (Geuter, 2012), allowing the client to choose the arts modality/ies most aptly representative of their experiences. They reflected, that having a range of coconstructive techniques available may help clients extend their agency, allowing them to make sense of their experiential story and find their 'personal truth' (McLeod, 2013).

A variety of clinical experiences that highlight the utility of integrative and arts-based therapies have been brought together and reflected upon to inform this project. LDM - an integrative psychologist who uses hypnotherapy, EMDR and other non-verbal creative approaches - reflected on the helpfulness of being able to adapt psychological approaches to the needs and preferences of individual clients. Particularly moving reflections concerned the witnessing of survivors of physical and sexual abuse reclaiming a sense of personal agency and space around their bodies using dance and movement methods, while another client, a physicist, made a mobile of various objects representing traumatic experiences, balancing the weights according to the impact these had upon her.

A client of AP, who suffered with depression, anxiety and trauma, described the experience and benefits of DMP sessions:

"When I had to push the wall as hard as I could, I pictured... all these bad things were like in this wall and I could just push it away and... It was quite hard hitting because I'd never thought that I would be able to do something like that... I was in control of those thoughts, and I could push it away... it's hard to explain what I do but I change and I'm able to put my thoughts into like picturing them physically... It was weird thinking about things in a whole different way... I could decide what I was going to do with my body... it felt really good to be in control because everything else in my life, I've got no control over." 
While this client had previously received counselling-based talking therapy, it was only through DMP and the use of various modalities leading to the physical intervention referred to above, that she felt such a profound shift in her mind-set and lived experience.

Clients report helpful factors from disparate orientations of therapy, with common areas of overlap between the talking therapies (client factors, therapeutic alliance, model/technique, and placebo/expectancy; Wampold, 2015) and arts psychotherapies (therapeutic alliance, insight, expression, interaction, interpretation and narrative integration; Karkou \& Sanderson, 2006; Colbert \& Bent, 2017). However, which therapeutic techniques, orientations or expressive modalities are most useful depends on the unique client-therapist-context and may change over time (McLeod \& Sundet, 2015). Therefore, integrating creative methods in a client-led manner enables the therapist to offer the most appropriate and acceptable intervention at the right time, while adopting a pluralistic approach to the client journey.

Pluralism has been described as a meta-model of therapy integration, in which client and therapist collaborate in deciding which approach(es) would work best for the individual client, without the need for theoretical coherence, or adherence to one universally-valid theory (Cooper \& McLeod, 2011; McLeod \& Sundet, 2015). Central to this practice, as with other therapies, is the therapeutic alliance or relationship, typified by the person-centred ethos (Cooper, 2015) and a 'non-expert' stance that allows for unfolding of mystery. Hence, the therapist 'comes alongside' and allows the work to be led by the client, implementing and exploring techniques felt to be most salient.

Previous innovators have attempted to amalgamate creative therapies in a way that spans different arts modalities. Natalie Rogers' (1993) Creative Connection builds upon client-centredness by listening for client language suggestive of a preferred arts modality as a basis for exploration, before developing less dominant modes, continually returning to the 'expert-client', their senses and imagination, to determine the next direction. Knill, Levine and Levine's Intermodal Expressive Arts Therapy (2005) follows a similar order, using the client's dominant modality to begin exploration, subsequently centring on the client's internal sensation to determine how to amplify or use alternative art forms to enable client expression and exploration of other perspectives. Implementing the client's 'felt sense', FocusingOriented Art Therapy (Rappaport, 2014) uses six steps of sensing and focusing (Gendlin, 1981) to structure therapy utilising any arts modality, returning to the client's felt sense to consider new knowledge, evaluate and direct activities. Lusebrink's (2015) Expressive Therapies Continuum arranges activities along a continuum from kinaesthetic/sensory (exploration), perceptual/affective imagery (engaging) to cognitive/symbolic integration (structuring). Other approaches involve connecting to spiritual aspects (Malchiodi, 2003). 
Such integrative arts models show areas of overlap in their approaches, especially in returning to the client's own felt sense (Gendlin, 1981) and imagination as a guiding principle. However, they fall short in incorporating evidence-based research findings identifying which ingredients of therapy are felt by clients to have been most useful in depression recovery. A qualitative review of client-identified helpful events in therapy (Timulak, 2007) included just one study focusing on depressed clients, in which creative therapies were not taken into account. Another review did focus upon change processes in depressed adolescent clients (Webb, Auerbach \& DeRubeis, 2012), yet was limited to CBT treatment only. The authors are not aware of reviews of client-reported helpful factors for depression specifically, or any reviews incorporating a variety of talking and arts therapies.

Given that current IAPT treatments show limited effectiveness for clients with depression, it is necessary to find a way to offer a combination of evidence-based active ingredients from different traditions and orientations, reported to be helpful in clients' depression recovery. These should be integrated in a way that spans and extends beyond previous attempts to implement multiple approaches or modalities offered by previous integrative models. Hence, by incorporating findings from both mainstream therapies and arts-based approaches, the creation of a pluralistic and creative metaapproach may extend the 'radical eclecticism' of pluralism beyond any current limits, in a way that engages and benefits clients with depression.

\begin{abstract}
Aims
This paper presents an interdisciplinary synthesis of key active ingredients in psychological treatment for depression, from both talking therapies, and creative arts-based approaches. Further, we aim to incorporate these synthesised findings to construct and present an overarching framework for creative, pluralistic arts-based therapy for depression. Lastly, we offer an example of a group therapy workshop based on this new approach, to be piloted with clients and practitioners within an inner city IAPT service.
\end{abstract}

\title{
Methods
}

\section{Orientation and design}

Mirroring our therapeutic stance, a pluralistic research orientation (Barker \& Pistrang, 2005; EasterbySmith, Golden-Biddle \& Locke, 2008) informed our interdisciplinary approach to inductive data acquisition, exploration and synthesis. The main research method was a Thematic Synthesis of relevant research findings (Thomas \& Harden, 2008). In tandem with this literature-based method, we posited the findings against our own ethnographic and experiential knowledge in a deepening and unfolding 
process of Crystallization (Ellingson, 2009), using some creative explorations of the topic to gain additional perspectives on the findings (Artistic Enquiry; Hervey, 2000).

\section{Pluralistic sources of evidence for a pluralistic therapy}

Our research design, as implied by 'pluralistic', was not purely literature-based. Barker and Pistrang (2005) state the importance of using the best combination of methods to investigate the research question(s), rather than confining methodology to strict conventions, in accordance with the rationale of a mixed methods approach (Creswell, 2014). In this study we have gone beyond the mixing of data from conventional research methods to add arts-based approaches influenced by ideas proposed by Hervey (2000) in Artistic Inquiry.

Valuable autoethnographic information situated within the researchers themselves provided knowledge and experience, grounded within real life and practice, to also take into consideration. Some researchers experimented creatively with the themes emerging from data analysis in order to understand them experientially through movement, creative wording, and performative material (Griffin \& Thurston, 2018). Other researchers brought with them a wealth of experience working with both talking and nonverbal methods. Therefore, appropriately framed personal, professional and creative experiences enhanced our approach to interpretation. An additional rationale for incorporating more intuitive and non-linguistic perspectives was that our client-led treatment would involve a reliance on a certain level of intuition and non-verbal approaches, so it appeared fitting to take this approach as researchers in contemplating the evidence. This contextualised and embodied knowledge, removed from linguistic representations in the literature, crystallized and enriched the literature findings of what may work in practice, and was invaluable in creating a pilot experiential workshop to be delivered within the IAPT context.

\section{Pluralism in thematic synthesis}

For our thematic synthesis, we were particularly focused on published studies on retrospective client perspectives. However, as some quantitative findings contain aspects of qualitative data (Thomas \& Harden, 2008), a range of other research data (therapists' perspectives, outcomes-based data) were reviewed concerning helpful factors for clients in treatment for depression, and incorporated if felt especially relevant with regards to client needs.

\section{Search strategy}

Researchers individually searched for papers on a range of therapy types: CBT, Cognitive Therapy, Behavioural Activation for Depression, Counselling for Depression, Psychodynamic, Pluralistic, Integrative, Arts (including DMP, Dramatherapy, Art Therapy and Music Therapy) and selfmanagement/other individual strategies. 
Inclusion criteria were as follows: published at any time, detailing client-reported helpful factors/ingredients which made their therapy effective (or not), written in English. The emphasis was on retrospective qualitative client reports, but also included were therapist reports of what clients found helpful, and to a lesser extent, quantitative outcomes-based studies of helpful factors and their effects, but only if they related to client evaluations of helpful therapy aspects. Only papers specific to depression were included.

Key words entered into electronic databases (including PsycINFO; Science Direct, SCOPUS and Google Scholar) included the name of the therapy itself (for example 'CBT' or 'cognitive behavioural therapy') and 'helpful factors'; 'helpful aspects'; 'client-reported'; 'client perspectives'; 'client views'; 'depression'. Authors also hand-searched in journals for papers of interest, or presented research already possessed on the topic, including $\mathrm{PhD}$ theses or other grey literature that met the inclusion criteria.

Purposive sampling of papers was used, in order to reach an optimal level of conceptual saturation. Searching continued until either a) further searching failed to add conceptually to the substantive array of data within each of the therapy types, or b) no more studies could be found.

\section{Quality assessment}

In assessing papers for inclusion during the search, we were guided by Tomas and Harden's (2008) guidelines for assessing quality of studies in thematic synthesis. Briefly, these relate to the reporting of aims, context, rationale, methods and findings, establishing the reliability and validity of data collection, analysis and findings, and appropriateness of study methods for uncovering findings about client perspectives on what features are helpful in therapy for depression.

\section{Data Extraction}

Based on their quality and appropriateness for answering the research question, a total of 14 suitable papers for CBT were analysed, six for Cognitive Therapy, seven for Behavioural Activation for Depression, nine for Counselling for Depression, 23 for integrative, pluralistic and psychodynamic, 17 for Arts therapies, and two for self-management/other. Key findings from these studies were collated verbatim into a table, before synthesising thematically.

\section{Thematic synthesis}

We used Thematic Synthesis (Thomas \& Harden, 2008) to collate findings from the studies. This approach to analysing secondary qualitative data, follows the same basic steps as Thematic Analysis (Braun \& Clarke, 2006), except the data is composed of previous authors' findings. These steps are as follows: 1. Free coding of the original extracted findings, 2. Grouping of similar free codes into 
descriptive categories, 3. Generating analytical themes that emerge from and step beyond the descriptive categories.

Individual researchers undertook duplicate and concurrent analysis of the data for each therapy type for the initial stages. Data were first-order coded for pertinent active ingredients of therapy, and these codes examined for similarities and differences, grouping them into second-order descriptive categories. Next, the researchers came together to compare codes, any relevant notes/contextual information and resolve any interpretive differences, before collaboratively agreeing on the overarching themes within the data for that therapy type. These themes were collated onto a master document, which was then added to after the analysis of each therapy type. All themes were then assimilated, resolving any overlaps, to arrive at a full list of themes across therapies.

\section{Deepening understanding through crystallization}

In their guide to Thematic Synthesis, Thomas and Harden (2008) state that in interpreting analytical themes, reviewers 'go beyond' the initial data to generate new interpretive constructs and meanings. We interacted and experimented with the themes generated, thus deepening and refining our understanding of the data in a process of crystallization (Ellingson, 2009). Some researchers reflected upon how the themes related to their own experiences as both therapists and clients, and others engaged with multimodal artistic enquiry (Hervey, 2000) using movement, creative writing and verbalisation to identify how their own long-term creative explorations related to the developing framework, using the developing thematic framework as an impetus for artistic enquiry. The emerging material from these enquiries helped to validate and deepen understanding of the qualitative findings, enabling further emphasis and refinement of some subthemes.

\section{Applied integration of helpful therapy features and arts modalities}

After the synthesis of thematic findings, it was necessary to integrate the helpful factors in an applied way. In order to construct the basis of an evidence-based yet practical template for the new therapeutic treatment, we consulted other integrative models of multimodal therapies (those which use a mixture of creative modalities as well as verbal mechanisms). Features of these multimodal therapies - Rogers' (1993) Creative Connection, Knill, Levine and Levine's Intermodal Expressive Arts Therapy (2005), Focusing-Oriented Art Therapy (Rappaport, 2014), Lusebrink's (2015) Expressive Therapies Continuum and multimodal Expressive Therapies (Malchiodi, 2003) - are described in the introduction. Similarities and differences between integrative models were evaluated: broadly, they present considerations around establishing space, safety and a client-led ethos, cultural and biological/inherited contexts, multilevel phenomenological experience, transitions between these levels (inter- or multi- 
modal transfer, superimposition, amplification), and processes for exploring, expanding, deepening client awareness. We considered these features in light of our thematic findings as well as our practitioner-inherent experiences of creative therapy, informing the structure and material for the pilot experiential workshop.

\section{Results}

Table 1 presents themes and subthemes of helpful factors in psychotherapeutic treatment for depression, integrated from client-reported findings across different psychotherapies, crystallised by the researchers' experiential knowledge and creative explorations.

Table 1. Findings from Thematic Synthesis of Client-Reported Helpful Factors

\begin{tabular}{|c|l|}
\hline \multicolumn{1}{|c|}{ Theme/subtheme } & \\
\hline $\begin{array}{l}\text { 1. Tailored structure and } \\
\text { content to fit the client }\end{array}$ & $\begin{array}{l}\text { The broad features and parameters of the therapy } \\
\text { package and of each session }\end{array}$ \\
\hline a) Effective timing & $\begin{array}{l}\text { Therapy commencement, schedule and number of } \\
\text { sessions tailored to client/group }\end{array}$ \\
\hline b) Structured yet flexible variety & $\begin{array}{l}\text { Well-organised, malleable content both in-session and out } \\
\text { e.g. homework; boundaried autonomy in tasks; unique } \\
\text { sessions/activities }\end{array}$ \\
\hline c) Prompting & $\begin{array}{l}\text { Reinforcing client behaviours/strategies where necessary } \\
\text { to help keep 'on track', e.g. through text messaging }\end{array}$ \\
\hline d) Cultural adaptation & $\begin{array}{l}\text { Appropriate and relatable group-specific content e.g. } \\
\text { tailored to different social groups }\end{array}$ \\
\hline e) Evolution of tasks & $\begin{array}{l}\text { Smooth, appropriately paced transition between different } \\
\text { ways of working (e.g. sensory levels, arts modalities, solo } \\
\text { to group work, development of themes or expressive } \\
\text { material) }\end{array}$ \\
\hline & $\begin{array}{l}\text { Specific features or processes within the clients' } \\
\text { inter/intra-personal repertoire that clients report have } \\
\text { been helpful to target in therapy }\end{array}$ \\
\hline & 2.
\end{tabular}




\begin{tabular}{|c|c|}
\hline $\begin{array}{l}\text { a) Increasing awareness and } \\
\text { insight }\end{array}$ & $\begin{array}{l}\text { Learning about self and depression; Self- and other- } \\
\text { schemas/concepts and relationships; New understanding, } \\
\text { conceptualising or reframing of problems }\end{array}$ \\
\hline b) Learning skills to manage self & $\begin{array}{l}\text { Learning to manage and balance vitality, emotions, } \\
\text { cognitions including rumination, and day-to-day } \\
\text { behaviours }\end{array}$ \\
\hline $\begin{array}{l}\text { c) Integrating personal material } \\
\text { \& narrative }\end{array}$ & $\begin{array}{l}\text { Finding meaning through integrating a personal narrative, } \\
\text { resolving past conflicts, bringing together personal } \\
\text { story/motif/metaphor, revealing way(s) forwards }\end{array}$ \\
\hline $\begin{array}{l}\text { d) Fostering social support \& } \\
\text { satisfaction }\end{array}$ & $\begin{array}{l}\text { Developing positive personal relationships, network- } \\
\text { building and frequent/regular purpose/reward in everyday } \\
\text { life }\end{array}$ \\
\hline $\begin{array}{l}\text { 3. Fundamental relational } \\
\text { skills and features }\end{array}$ & $\begin{array}{l}\text { Fundamentals of the therapeutic space, process and } \\
\text { relationship (therapist, client and/or group) }\end{array}$ \\
\hline a) Safe place & $\begin{array}{l}\text { Comfort and containment in therapy space or } \\
\text { organisation }\end{array}$ \\
\hline $\begin{array}{l}\text { b) Coherent explanation of } \\
\text { therapy }\end{array}$ & $\begin{array}{l}\text { Building trust, confidence and hope through a clear } \\
\text { explanation of process/ mechanism(s) }\end{array}$ \\
\hline $\begin{array}{l}\text { c) Warm, supportive } \\
\text { alliance/group cohesion }\end{array}$ & $\begin{array}{l}\text { Therapeutic and/or group relationship characterised by } \\
\text { empathy, unconditional positive regard, full } \\
\text { psychological 'contact', 'holding', comfort and } \\
\text { reassurance, inclusivity }\end{array}$ \\
\hline d) Skilled, responsive balancing & $\begin{array}{l}\text { Therapist's attunement with client needs in order to } \\
\text { precisely negotiate and modulate different dynamics, } \\
\text { challenges and boundaries as appropriate to foster client's } \\
\text { development. } \\
\text { Examples: Directing vs. non-directing, Affirming vs. } \\
\text { challenging, Reassure vs. confront, Interpreting vs. } \\
\text { holding, Guiding vs. exploring, Lead vs. follow, Depth } \\
\text { vs. smoothness, Expert vs. 'friend', Distancing vs. } \\
\text { disclosing }\end{array}$ \\
\hline $\begin{array}{l}\text { e) Interpersonal collaboration- } \\
\text { sharing with others }\end{array}$ & $\begin{array}{l}\text { Through task-orientated group-work and observing } \\
\text { relational dynamics within self (client) and responses } \\
\text { to/from others in group. }\end{array}$ \\
\hline
\end{tabular}




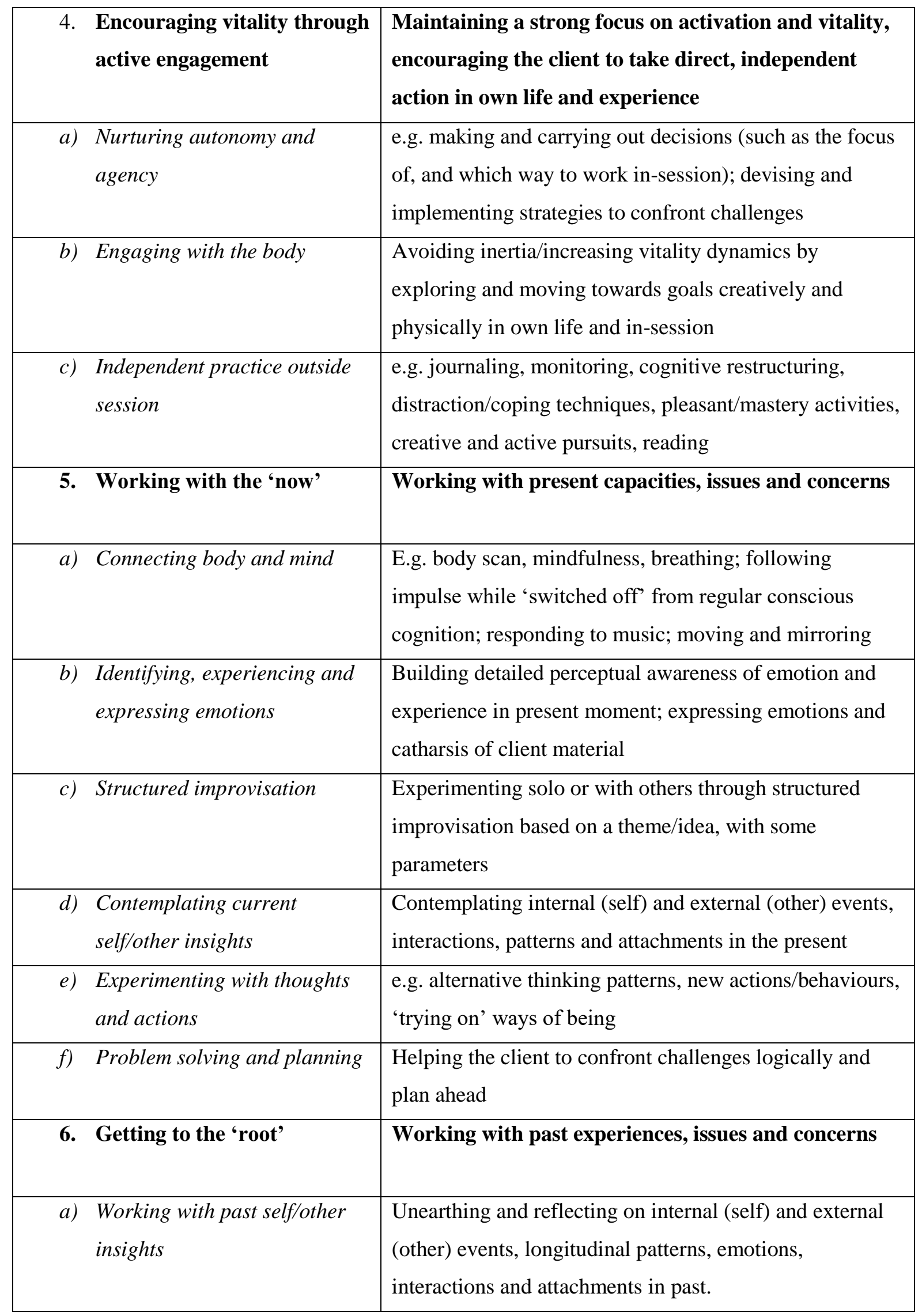




\begin{tabular}{|c|l|}
\hline b) Bridging the insight gap & $\begin{array}{l}\text { Linking past events and current reality, reorganizing their } \\
\text { implications for personal 'narrative', capacities } \\
\text { developed and coherent self-understanding. }\end{array}$ \\
\hline c) Nurturing self-regard & $\begin{array}{l}\text { Normalizing and accepting aspects of past self to enhance } \\
\text { self-regard. Practicing helpful/positive self-reflection. }\end{array}$ \\
\hline 7. Bringing it all together & $\begin{array}{l}\text { Recognising, celebrating and integrating useful } \\
\text { material back to one's life }\end{array}$ \\
\hline a) Identifying core values & $\begin{array}{l}\text { Identifying personal values for future direction and } \\
\text { action, towards a new narrative }\end{array}$ \\
\hline c) Concepts & $\begin{array}{l}\text { Integrating new self-concepts that culminate the end point } \\
\text { of the therapeutic journey through expressive narrative } \\
\text { (story, choreography, artwork, poem etc) }\end{array}$ \\
\hline c) Practising new ways of being & $\begin{array}{l}\text { Refining the self-concepts through reflection and/or } \\
\text { repetition }\end{array}$ \\
\hline d) Sharing creative work with \\
others & $\begin{array}{l}\text { Exhibiting/performing this work to self and others if } \\
\text { appropriate }\end{array}$ \\
\hline
\end{tabular}

Findings revealed a hierarchy of seven themes and 30 subthemes, arranged by how 'foundational' or primary they appear to be in the therapy approach. Theme 1, 'Tailored structure and content to fit the client', is presented first because the planned structure and content of the therapy package is by necessity the initial consideration that a therapist or organisation must make. This leads to considering ways in which clients can focus on their 'Client targets' as an important reference point to kick start the therapeutic process (theme 2). 'Fundamental relational skills and features' (theme 3 ) sits at the core of what the therapist does in the session and the overall attitude of the therapist, in relation with the client(s). The active nature of the intervention and overall ethos of the approach is evident in 'Encouraging vitality through active engagement' (theme 4), which stems from client reported helpful factors relating to activation and empowerment through doing. Themes 5, 6 and 7 clarify ways of working in the here and now, in the past and moving towards integration. Thus, supporting the client to bridge the gap between past events and current reality, while extending towards the future by capitalising on the lessons learned and capacities developed for coherent self-understanding.

The active and creative thread (theme 4) runs through many aspects of the model, featuring both in the evolving tasks in the structured content of therapy (theme 1e), and in the way in which the tasks and activities in-session are to be engaged - using client's preferred modality/ies, or combinations of talking/verbalising, writing, imagery, symbolism, movement, sound, story, other creative media 
(themes 5,6 and 7). This approach also offers a helpful way to conclude the therapy journey creatively (theme 7 - Bringing it all together).

Unhelpful factors found in the thematic synthesis did not make the final edit because they all represented the opposite of some of the helpful factors featured. Therefore, by adhering to the recommended package of active ingredients, therapists would be avoiding these unhelpful factors. For example, one unhelpful factor 'Not modulating the intensity of challenging aspects of therapy (lack of modulation causing distress/unsafety to client)' is neutralised by the helpful factor 3d) 'Skilled, responsive balancing'.

Although fairly complex and theoretical, these findings offer the key 'building blocks' with which therapists and clinicians might devise a pluralistic psychotherapeutic treatment package for depression, appropriate to their specific client group and context. Based on these building blocks, the authors assembled a single-session pilot workshop to be trialled within an inner-city IAPT service with a small $(<10)$ group of clients, and another of IAPT clinicians. Table 2 presents a chronological outline of this pilot intervention and highlights how it has been informed by the theoretical basis of Table 1's findings and/or potential active ingredients that may be operationalised by the activities (N.B. wording and features of the workshop should be adapted to suit the population and context). 
Table 2. Outline and Theoretical Underpinnings of IAPT Pilot Intervention

\begin{tabular}{|c|c|c|}
\hline Task & Description & $\begin{array}{l}\text { Theory/ } \\
\text { 'active } \\
\text { ingredients' }\end{array}$ \\
\hline Introduction & $\begin{array}{l}\text { Facilitators and clients introducing selves } \\
\text { Introducing time boundaries and any contingency plans (telephone/email follow-up) } \\
\text { Introducing a brief chronological preview of workshop; normalizing any client concerns about their competence }\end{array}$ & $\begin{array}{l}3 \mathrm{c} \\
1 \mathrm{a} \\
1 \mathrm{e}, 3 \mathrm{~b}, \mathrm{c}\end{array}$ \\
\hline $\begin{array}{l}\text { Safety, ethical } \\
\text { contracting and } \\
\text { housekeeping }\end{array}$ & $\begin{array}{l}\text { Outlining potential effects of workshop and safety precautions } \\
\text { Outlining participant responsibility for safety in activities, the right to withdraw and inviting clients to express any } \\
\text { initial needs } \\
\text { Collaboratively establishing ground rules (i.e. confidentiality, respect, non-judgemental attitude) } \\
\text { Housekeeping }\end{array}$ & $\begin{array}{l}3 \mathrm{a}, \mathrm{d} \\
3 \mathrm{a}, \mathrm{c}, 4 \mathrm{a} \\
1 \mathrm{e}, 3 \mathrm{a} \\
3 \mathrm{c}, \mathrm{e}, 4 \mathrm{a} \\
3 \mathrm{a}\end{array}$ \\
\hline $\begin{array}{l}\text { Goal setting, } \\
\text { sharing and rating }\end{array}$ & $\begin{array}{l}\text { Inviting participants to set a small, manageable and immediate goal to work on during workshop, e.g. changing a } \\
\text { feeling state or clarifying a problem or dilemma } \\
\text { Participants sharing their goals in pairs. Facilitator(s) check goals are appropriate for workshop context } \\
\text { Participants writing down their goal and rating it on the goal worksheet, according to how close they are to } \\
\text { achieving this on the scale } 0-10 \\
\text { Inviting participants to share their goal and/or numerical rating with the group }\end{array}$ & $\begin{array}{l}1 \mathrm{~b}, 4,2 \mathrm{a} \\
3 \mathrm{e}, 5 \\
5 \\
3 \mathrm{e}, 4 \mathrm{~d}, 5\end{array}$ \\
\hline
\end{tabular}




\begin{tabular}{|c|c|c|}
\hline $\begin{array}{l}\text { Body scan and } \\
\text { emotional check-in }\end{array}$ & $\begin{array}{l}\text { Experiential mindfulness-based body scan (attending to body, breathing, sensation and affect) } \\
\text { Sensing a connection to the goal: participants invited to sense how/where the goal is perceived in the body } \\
\text { (normalize any difficulties in doing this) } \\
\text { Inviting feedback on their experiences of this }\end{array}$ & $\begin{array}{l}5,4 \mathrm{~b} \\
5,4 \mathrm{~b} \\
(2 \mathrm{c}) \\
1 \mathrm{e}, 3 \mathrm{c}, 2 \mathrm{a}, 5\end{array}$ \\
\hline $\begin{array}{l}\text { Modelling } \\
\text { expressive arts } \\
\text { modalities }\end{array}$ & $\begin{array}{l}\text { Briefly practice using the three different arts modalities }{ }^{1} \text { (making marks on paper, writing creatively on impulse, or } \\
\text { movement) to respond to sensations and perceptions when focusing on different body parts. } \\
\text { Inviting participants to share their experience of this, and to notice which modality/ies felt most natural to use for } \\
\text { the next activity }\end{array}$ & $\begin{array}{l}1 \mathrm{~b}, \mathrm{e}, 5,4 \mathrm{a}, \mathrm{b} \\
5 \\
1 \mathrm{~b}, \mathrm{e}, 2 \mathrm{~d}, 5,4 \mathrm{a}\end{array}$ \\
\hline Creative expression & $\begin{array}{l}\text { Making participants aware that they will be sharing their creative expression in pairs. Normalizing any potential } \\
\text { challenges with this activity } \\
\text { Inviting participants to sense and focus in on bodily responses to their goal and allowing their imagination to evoke } \\
\text { images, colours, words, textures, rhythms, sounds, movements, sensations etc in response to this experience } \\
\text { Inviting participants to work with their preferred modality/ies in order to express and creatively extend this inner } \\
\text { experience }\end{array}$ & $\begin{array}{l}1 \mathrm{e}, 3 \mathrm{a}, \mathrm{c} \\
2 \mathrm{a}, 5 \\
1 \mathrm{~b}, \mathrm{e}, 5,4 \mathrm{a}, \mathrm{b}\end{array}$ \\
\hline $\begin{array}{l}\text { Reviewing goals } \\
\text { and ratings }\end{array}$ & Inviting participants to review original goals and repeat rating, again using the 1-10 scale and writing this down & $3 \mathrm{~b}, 2 \mathrm{a}, \mathrm{e}, 5$ \\
\hline
\end{tabular}




\begin{tabular}{|c|c|c|}
\hline $\begin{array}{l}\text { Whole group } \\
\text { sharing and } \\
\text { creating }\end{array}$ & $\begin{array}{l}\text { Inviting participants to share their experiences of the workshop, uncertainties/questions, anything they have learned } \\
\text { from the experience, and how they will apply this learning in their lives over the coming week } \\
\text { Inviting all participants to creatively express their final responses to this group experience, by making marks or } \\
\text { words on a large piece of paper (group drawing), or creating a collective movement }\end{array}$ & $\begin{array}{l}\text { 3e, } 2,4,5,6,7 \\
1 \mathrm{e}, 3 \mathrm{e}, 2 \mathrm{~d}, 5,7\end{array}$ \\
\hline Closure & $\begin{array}{l}\text { Participants choosing whether to take their creative work or leave it behind } \\
\text { Providing participants with a list of resources in case of feeling upset after the session } \\
\text { Allowing extra time in the room in case participants want to stay and connect with each other or talk informally } \\
\text { with facilitators after the session }\end{array}$ & $\begin{array}{l}4 a \\
3 a \\
3 c, 2 d\end{array}$ \\
\hline
\end{tabular}

1. For the purpose of this pilot workshop, participants are limited to a choice of three modalities - image making with pastels, creative writing, or creative movement. This is so as to provide some choice of widely-familiar modalities, without overwhelming with too many choices in the initial workshop. Longer-term interventions may use any number of arts modalities e.g. sculpture, sound making, others. 
The above outline comprises a number of activities and steps to undertake in facilitating a single 90minute pilot workshop, as well as the rationale and/or potential active ingredients involved in the activities. The activities themselves will be by necessity of time limitation, very brief, and therefore the workshop provides only a 'taster' of the main tenets and activities of the approach, the order and transitions that might be followed, and the rationale for each.

Because of the brief activities and single-session nature of the workshop, deeper, longer-term therapeutic aims, features and outcomes (normally achievable in the context of a longstanding and therapeutic alliance) are unlikely to be met, such as prompting between sessions (1c), achieving full psychological 'contact' (3c), integrating a personal narrative (2c), building a supportive social network and regular reward/enjoyment in life (2d), unearthing and reflecting on insight around the past (6a), positively integrating past events, strengths/achievements into self-narrative (6b) and unearthing core values (7a). These features and objectives are more likely to be developed and targeted over a series of therapy sessions.

Not explicitly stipulated within table 2 are incidental considerations such as room size/features, adaptations for holding the workshop with the IAPT clinicians as opposed to clients, the optional use of music and how to deal with disruptions such as clients interpreting/dominating/chit-chat, although these matters broadly fall under the remit of Safe place, Cultural adaptation, Structured yet flexible variety/Structured improvisation, and Skilled, responsive balancing, respectively.

\section{Discussion \& Conclusions}

We aimed to synthesise findings from both arts- and mainstream-therapeutic evidence with interdisciplinary collaboration, to present a set of key ingredients and helpful factors in the treatment of depression, structured into a coherent new pluralistic approach that extends beyond current integrative and arts models of therapy. Crystallised from the sum of published and experiential evidence, we established seven main themes which illuminate key tenets of the new approach: Tailored structure and content to fit the client, Client targets, Fundamental relational skills and features, Encouraging vitality through active engagement, Working with the 'now', Getting to the 'root' and Bringing it all together. Within these seven themes, 30 subthemes detail the specific components which may be implemented in each of these areas. At the heart of the approach lies a client-led ethos within the safety of a strong and attuned therapeutic relationship, to ultimately encourage clients to become self-led in regaining their vitality and engagement with life.

Our secondary aim was to apply these findings in a real-world context, by devising an example workshop for a specific set of clients, using the new framework to guide our session plan. We found that the order of activities planned for the workshop naturally reflected the structure of the framework 
- beginning with the foundational and preliminary considerations, then to the safety of the therapeutic relationship(s), then to the clients' own target setting, followed by experiential activities and subsequent personally-reflective meaning-making, and finally concluding the experience in a shared expression. Throughout these activities, the thread of active engagement is built in by providing client choice and autonomy, inviting them to engage the whole self in 'doing' and moving activities. Hence, the proposed workshop matches the theoretical model in a way that chronologically matches the layers (fundamental tenets, to specific tasks) of the framework.

The findings of our thematic synthesis support recent and ongoing DMP research findings, which propose that key processes involved in treating and alleviating depression include (i) connecting with the body, (ii) forming relationships (iii) unearthing and processing difficult emotions (iv) integrating emotional material (Karkou et al., in press). Indeed, these facets are a close match with some of our active ingredients under the themes 'client activation', the 'therapeutic relationship' and 'working with 'now', 'getting to the root' and 'bringing it all together'. Further supporting the connection with the body, a recent Cochrane review (Meekums, Karkou \& Nelson, 2015) proposed some similarly bodyoriented theoretical mechanisms: non-verbal communication, kinaesthetic responding and embodied empathy. In addition, the review highlights the potential 'unblocking' of vitality - energy, stamina, and physical or mental vigor, reflecting physical and emotional components of wellbeing (Deng, Guyer \& Ware, 2015) - through movement and creative processes. This aligns somewhat with our 'Encouraging vitality through active engagement' theme, which proposes a strong focus on client agency and physical engagement to support vitality and overcome inertia. It also strongly ties in with Stern's (1995) theories on vitality dynamics arising from physical and creative actions and interactions, as opposed to more passive, inert experiences and speaks to research on physiological and neurological research in dance (see Jola \& Calmeiro, 2017; Blazing, 2017).

Furthermore, the centrality of symbolism and metaphor in movement and imagination (Karkou et al., in press) - to increase client-therapist closeness, safely process distressing content and creatively apprehend change. Our framework features the use of arts modalities to engage metaphor throughout themes five through seven. Finally, the inclusion of physically creative acts in these themes and especially 5a) Connecting body and mind, are supported by empirical findings on embodied affectivity (Fuchs \& Koch, 2014) - that is, the circular effects of 'moving' (action, expression, movement and sensation) and 'being moved' (perceptions of affective stimuli in the external environment) - to progress understanding and promote vitality.

Extending beyond DMP research, the framework features key ingredients which are derived from other evidence-based approaches, for example active engagement strongly aligns with principles of Behavioural Activation (a behavioural therapy focused on breaking the cycle of inertia seen in depression; Veale, 2008). The centrality of the therapeutic relationship echoes common factors research 
(e.g. Wampold, 2015) and Humanistic/Rogerian orientations, yet beyond this, evidence-based techniques have been incorporated such as negotiating client targets and goals, planning, problem solving, setting homework and skills training, which are more affiliated with CBT (Beck, 2011). Nevertheless, the means by which the targets are engaged - through sensory, embodied and creative processes - are shared with arts-based, body and mindfulness orientations (Rappaport, 2013).

Within our framework, we do not see the methods involved (from supposedly opposing approaches) as being mutually-exclusive. Schmid (2005) defines creativity as: "An innate capacity to think and act in original ways, to be inventive, to be imaginative and to find new and original solutions to needs, problems and forms of expression. It can be used in all activities. Its processes and outcomes are meaningful to its user and generate positive feelings" (p6). Therefore, the more reason-based 'problem solving' (e.g. of more cognitive/rational therapies) and the depth-based illumination of material outside of conscious awareness (e.g. through the creative act) are seen as mutually augmentative - one may inspire, enrich and extend the other within our pluralistic framework.

While the use of spontaneous creative acts and an embodied locus of attention have the potential to transcend the limits of talking therapies, these aspects nevertheless pose a challenge for many and may invoke feelings of anxiety in some clients. Clients may lack the confidence to engage with the inherently unpredictable nature of the creative act and may fear 'putting themselves out there' (Parsons \& DubrowMarshall, 2018) through creative expression. Hence, it is necessary to 'scaffold' a clear, secure and reliable structure within sessions, and to evolve tasks gradually and at a client-led pace, as set out in our framework (1e - Evolution of tasks). The therapist must use their competencies of Skilled, responsive balancing (theme $3 \mathrm{~d}$ ) to sensitively and precisely negotiate and modulate levels of directive versus nondirective elements, and the depth (impact) and smoothness (client-perceived safety) of the work (Stiles et al., 1994). Particularly in the group context, a more directive approach to structure activities is necessary, and setting of parameters for depth/difficulty of individual client material, to contain the process of multiple clients simultaneously. Our pilot workshop implements this structure and parameters, while offering client-led options within these limits as appropriate for the population and setting. Finally, bearing in mind our client-led, pluralistic ethos, it is important to note that ultimately there are some individuals who are simply averse to the use of arts generally or therapeutically, and for these individuals no amount of structuring or negotiating will overcome their aversion to creative methods. This intervention might not be appropriate for them.

Throughout our approach, clients' active engagement is encouraged (theme 4) - instilling an overarching ethos of agency, autonomy, physical action and skill building throughout the other ingredients; in other words, developing clients' capacity to be self-led. This self-determination begins with the choosing of an immediate goal to work with in-session. The list of Client targets (theme 2) is based on changes reported by clients to have been helpful in treatment of depression. However, the list 
is not exhaustive, and the immediate goals chosen by clients may, at face value, bear little relation to these overall Client targets. Nevertheless, the client-led approach supports a view of the client as 'expert' and therefore we do not impose preconceived ideas about what they need to work on in a particular session.

As clinicians and researchers, we allowed our own creativity to guide our collaborative approach to the project - thus 'practising what we preach' in terms of modulating challenges, integrating perspectives, following creative interests and valuing imagination. We worked alongside a performance team who composed a movement and spoken word composition based on emergent findings of our research (Griffin \& Thurston, 2018). In this crystallisation of approaches, four elements stand out as beneficial to the overall process and worthy of mention here. Firstly, the centrality of a trusting relationship that is needed when working performatively, especially within the context of interdisciplinary collaboration where neither participant was an expert in the other's discipline. Notions of sharing internal phenomena expressively and co-constructing meaning lie at the heart of both the compositional/performative process, and of our therapeutic approach.

Secondly, the performance team experimented with different arts modalities, combining movement, spoken word and music to arrive at a complete composition that enabled and mobilised the full expression of inner experience, enacting movement metaphor across different disciplines to develop a shared movement and verbal language. Thirdly, the performance team contemplated the emergent themes, finding a high level of recognition in support of their own experiential findings. They were able to recognise the common practices of structured improvisation, relational dynamics and reflection across artistic and therapeutic practice, reporting that outcomes from the creative collaboration were comparable to those of therapy, i.e. a sense of extending one's repertoire, developing aptitude for embodied action, and accepting the wholeness of one's experience. Lastly, the experience of working 'holistically' - combining both empirically supported and subjective, experiential types of evidence has highlighted the overall value of working pluralistically.

It is important to note, reflexively, that although the review of published literature was undertaken collaboratively by a group of Psychologists, Dance Movement Psychotherapists and Counsellors, the therapists' background and preferences may have impacted the way data were sought and presented (Haynes, 2012). In interpreting, analysing and synthesising evidence, we may have perceived things that resonated with our personal and professional (therapeutic or research) experiences to date. This innate tendency has been acknowledged and mitigated as far as possible through checking in and dialoguing as a (diverse) team about the rationale for different decisions in the research process, and holding each decision up to the scrutiny of both tacitly-developed knowledge, and the rationallyselected research methodology we adopted from the beginning. 
Regarding the implications of the findings themselves, our creative treatment framework is not 'manualised' and therefore does not offer a step-by-step set of instructions to clinicians, rather it is an assemblage of principles and active ingredients, to be used with therapist and client discretion according to individuals and context. Whereas, the outline of a pilot workshop provides a limited, context-specific example only. The workshop is not intended to be a therapy or to work at great depth - indeed, it would be unsafe to do so under the circumstances of a single instance of experimental research. Hence, not all of the active ingredients have been explicitly operationalised within this workshop, and a longer-term intervention will be needed to demonstrate the full range of active ingredients as appropriate to the client/group. To this end, a manual for longer-term application of the approach should be developed and trialled.

\section{Conclusions}

Our thematic synthesis of helpful factors in therapy for clients with depression generated a framework of seven themes and 30 subthemes, which clinicians may implement using multimodal artistic and verbal methods with their clients. The findings align with previous purported mechanisms in Dance Movement Psychotherapy, while also extending beyond previous work to incorporate client views from all therapies, in a new meta-approach not previously attempted by other integrative models. At the heart of this new approach lies both the therapeutic relationship, and clients' active engagement, in order to enable both safety and vitality.

Our innovative research process has highlighted the value of interdisciplinary work, marrying the science and art of the researchers' psychological, psychotherapeutic, health and arts-based professional disciplines, perspectives and methods, enabling a multidimensional understanding of the findings and their application within both performance and therapy. Furthermore, we provide an example of how the blueprint of this meta-approach has been used to devise a specific pilot workshop to be trialled in an inner-city IAPT setting. However, neither the theoretical framework nor the pilot intervention constitutes a standardised treatment package, and therefore testing for efficacy or effectiveness is not yet possible. Further research is anticipated to evaluate the IAPT workshop and future objectives should be to conduct studies testing a more standardised version of the approach. Nevertheless, therapists of all orientations may find value in this embryonic creation by using their professional judgement as to which overarching tenets - or specific active ingredients - of the approach are felt to be appropriate to implement with their clients.

\section{References}


Parliament, House of Commons (2018). Mental health statistics for England: Prevalence, services and funding. (HC 6988 2018) [Online] London: The Stationary Office. Available from: https://researchbriefings.parliament.uk/ResearchBriefing/Summary/SN06988

Barker, C., \& Pistrang, N. (2005). Quality criteria under methodological pluralism: Implications for conducting and evaluating research. American Journal of Community Psychology, 35(3-4), 201-212.

Beck, J. S. (2011). Cognitive behavior therapy: Basics and beyond. New York: Guilford press.

Cooper, M. (2015). Core Counselling Methods for Pluralistic Practice. In Cooper, M., \& Dryden, W. (Eds.). The handbook of pluralistic counselling and psychotherapy, (pp. 80-93). London: Sage.

Cooper, M. \& McLeod, J. (2011) Pluralistic counselling and psychotherapy. London: Sage.

Creswell, J. W. (2014). A concise introduction to mixed methods research. California: Sage.

Deng, N., Guyer, R., \& Ware, J. E. (2015). Energy, fatigue, or both? A bifactor modeling approach to the conceptualization and measurement of vitality. Quality of Life Research, 24(1), 81-93.

Easterby-Smith, M., Golden-Biddle, K., \& Locke, K. (2008). Working with pluralism: Determining quality in qualitative research. Organizational Research Methods, 11(3), 419-429.

Ellingson, L. L. (2009). Engaging crystallization in qualitative research: An introduction. California: Sage.

Fuchs, T., \& Koch, S. C. (2014). Embodied affectivity: on moving and being moved. Frontiers in Psychology, 5, 508.

Gendlin, E. T. (1981). Focusing ( $2^{\text {nd }}$ ed). New York: Bentam Books

Geuter, U. (2012) Forms of vitality. Exploring dynamic experience in psychology, arts, psychotherapy, and development, by Daniel N. Stern. Body, Movement and Dance in Psychotherapy, 7(3), 235-239, DOI: 10.1080/17432979.2012.674062

Griffin, J., \& Thurston, S. (2018). 'Getting Out of Your Own Way' (dance and poetry performance), performed at Edge Hill University on 23 February 2018 and 13 June 2018, University of Bedfordshire 14 June 2018, Starptelpa: Riga Performance Festival, Riseba, Riga, Latvia 17 June 2018.

Hervey, L. W. (2000). Artistic inquiry in dance/movement therapy: Creative research alternatives. Springfield, Illinois: Charles C Thomas Publisher. 
Jola, C., \& Calmeiro, L. (2017). The Dancing Queen: explanatory mechanisms of the 'feel-good effect' in dance. In Karkou, V., Oliver, S., \& Lycouris, S. (Eds.). The Oxford handbook of dance and wellbeing. Oxford: Oxford University Press (pp.13-41).

Karkou, V., Genetti, A., Zubala, A., Aithal, S., \& Meekums, B. (in press). The Role of Dance Movement Therapy in the Treatment of Depression: From Clinical Practice to Research Evidence. Frontiers in Psychology.

Karkou, V., \& Sanderson, P. (2006). Arts therapies: A research-based map of the field. Edinburgh: Elsevier Health Sciences.

Knill, P. J., Levine, E. G., \& Levine, S. K. (2005). Principles and practice of expressive arts therapy: Toward a therapeutic aesthetics. London: Jessica Kingsley Publishers.

Lusebrink, V. B. (2015). Expressive therapies continuum. In Gussak, D., \& Rosal, M. L. (Eds.). The Wiley handbook of art therapy (pp.57-68). Sussex, UK: Wiley Blackwell.

Malchiodi, C. A. (2003). Expressive arts therapy and multimodal approaches. In Malchiodi, C. A. (Ed.), Handbook of art therapy (pp.106-117). New York: Guilford Press.

McLeod, J. (2013). Developing pluralistic practice in counselling and psychotherapy: Using what the client knows. The European Journal of Counselling Psychology, 2(1).

McLeod, J., \& Sundet, R. (2015). Integrative and Eclectic Approaches and Pluralism. In Cooper, M., \& Dryden, W. (Eds.), The handbook of pluralistic counselling and psychotherapy (pp. 158-171). London: Sage.

Meekums, B. (2002). Dance movement therapy: A creative psychotherapeutic approach. London: Sage.

Meekums, B., Karkou, V., \& Nelson, A. (2015). Dance movement therapy for depression. Cochrane Database of Systematic Reviews, 2, 1-54.

Parsons, A. S., \& Dubrow-Marshall, L. (2018). 'Putting Themselves Out There' Into the Unknown: Dance Movement Psychotherapy as Perceived by Five Educators and Three Pupils. Body, Movement and Dance in Psychotherapy. DOI: 10.1080/17432979.2018.1508073

Rappaport, L. (2013). Mindfulness and the arts therapies: Theory and practice. London: Jessica Kingsley Publishers.

Rappaport, L. (2014). Focusing-oriented expressive arts therapy. In Madison, G. (Ed.), Theory and Practice of focusing-oriented psychotherapy: Beyond the talking cure. (pp. 204-218). London: Jessica Kingsley Publishers. 
Rogers, N. (1993). The creative connection: Expressive arts as healing. Monmouth: PCCS Books.

Stiles, W. B., Reynolds, S., Hardy, G. E., Rees, A., Barkham, M., \& Shapiro, D. A. (1994).

Evaluation and Description of Psychotherapy Sessions by Clients Using the Session Evaluation Questionnaire and the Session Impacts Scale. Journal of Counselling Psychology, 41(2), 175185.

Timulak, L. (2007). Identifying core categories of client-identified impact of helpful events in psychotherapy: A qualitative meta-analysis. Psychotherapy Research, 17(3), 305-314.

Thomas, J., \& Harden, A. (2008). Methods for the thematic synthesis of qualitative research in systematic reviews. BMC medical research methodology, 8(1), 45.

Veale, D. (2008). Behavioural activation for depression. Advances in Psychiatric Treatment, 14(1), 29-36.

Wampold, B. E. (2015). How important are the common factors in psychotherapy? An update. World Psychiatry, 14(3), 270-277.

Webb, C. A., Auerbach, R. P., \& DeRubeis, R. J. (2012). Processes of change in CBT of adolescent depression: Review and recommendations. Journal of Clinical Child \& Adolescent Psychology, 4l(5), 654-665. 